Pfizer, Sanofi, Stephanie Wichuk: None declared, Praveena Chiowchanwisawakit: None declared, Terrie MacCosham: None declared, Joel Paschke: None declared, Désirée van der Heijde Consultant for: AbbVie, Amgen, Astellas, AstraZeneca, Bristol-Myers Squibb, Boehringer Ingelheim, Celgene, Daiichi, Eli-Lilly, Galapagos, Gilead, GlaxoSmithKline, Janssen, Merck, Novartis, Pfizer, Regeneron, Roche, Sanofi, Takeda, Union Chimique Belge, Robert B.M. Landewé: None declared, Walter P. Maksymowych Grant/research support from: Abbvie, Novartis, Pfizer, Consultant for: Abbvie, Boehringer, Celgene, Galapagos, Lilly, Novartis, Pfizer, UCB, Speakers bureau: Abbvie, Boehringer, Celgene, Galapagos, Lilly, Novartis, Pfizer, UCB

DOI: 10.1136/annrheumdis-2019-eular.330

\section{SAT0350 THE IMPACT OF FIBROMYALGIA ON SLEEP DISTURBANCE AND QUALITY OF LIFE IN PATIENTS WITH ANKYLOSING SPONDYLITIS}

Iryna Shapoval, Mykola Stanislavchuk, Larysa Perebetiuk. National Pirogov Memorial Medical University, Vinnytsya, Ukraine, Rheumatology, Vinnytsya, Ukraine

Background: Sleep disturbance is a very frequent symptom in patients with diseases associated with pain syndrome [1, 2]. Prevalence of sleep disorders in ankylosing spondylitis (AS) patients varies in a range of $35 \%$ to $90 \%$ [2]. One of the most common comorbid condition in patients with AS is fibromyalgia (FM), that can significantly worsen quality of life and sleep quality in patients with AS.

Objectives: The aim of this study was to evaluate the impact of FM comorbidity on sleep disturbance and quality of life in patients with AS.

Methods: One hundred and nineteen patients with AS according to modified New York criteria (mean age (M $\pm S D$ ) $42.23 \pm 11.5$ years; 21 women and 98 men) were enrolled in the study. FM was diagnosed based on the 1990 American College of Rheumatology classification criteria. All patients were asked to complete self-report questionnaires, including the Pittsburgh Sleep Quality Index (PSQI) and Ankylosing Spondylitis Quality of Life Questionnaire (ASQoL) to assess sleep disturbance and quality of life.

Results: Of the AS patients, $23(19.3 \%)$ met the criteria for FM. The patients were divided into two groups in terms of having or not having FM. Groups were representative for age and disease duration. Patients with AS and concomitant FM showed significantly increased frequency of sleep disturbance according to the PSQI. Only 26 patients with AS $(27 \%)$ scored $<5$ and indicated as "good sleepers", whereas all patients with AS and concomitant FM has poor sleep quality. In group with AS patients mean scores $(M \pm S D)$ of $P S Q I$ were $7.52 \pm 3.96$ and in group with AS+FM $-11.04 \pm 3.5(P<0,01)$. Table 1 shows detailed information on the sleep quality of patients with and without FM.

Table 1. Sleep Disturbances in patients with Ankylosing Spondylitis and Concomitan Fibromyalgia according to Pittsburgh Sleep Quality Index (sleep component scores)

\begin{tabular}{|c|c|c|c|}
\hline Component & $\begin{array}{c}\text { AS with } \\
\text { FM } \\
(n=23)\end{array}$ & $\begin{array}{c}\text { AS without } \\
\text { FM } \\
(n=96)\end{array}$ & $\mathbf{P}$ \\
\hline & $\overline{(M \pm S D)}$ & $(\mathrm{M} \pm \mathrm{SD})$ & \\
\hline Sleep quality & $1.78 \pm 0.74$ & $1.49 \pm 0.74$ & $\begin{array}{c}<, 05 \\
0,0\end{array}$ \\
\hline Sleep latency (time to fall asleep) & $2.00 \pm 0.85$ & $1.31 \pm 1.03$ & $\begin{array}{c}<, 05 \\
0,0\end{array}$ \\
\hline Sleep duration (hours of sleep) & $1.61 \pm 1.08$ & $1.16 \pm 1.02$ & $<<$ \\
\hline $\begin{array}{l}\text { Sleep efficiency (percentage of time asleep while in } \\
\text { bed) }\end{array}$ & $1.83 \pm 1.19$ & $0.85 \pm 1.15$ & $<<$ \\
\hline Sleep disturbances & $1.87 \pm 0.46$ & $1.32 \pm 0.55$ & $<<$ \\
\hline Use of sleep medication & $0.30 \pm 0.70$ & $0.15 \pm 0.53$ & NS \\
\hline Daytime dysfunction & $1.65 \pm 0.93$ & $1.23 \pm 0.91$ & $\begin{array}{c}< \\
0,05\end{array}$ \\
\hline
\end{tabular}

In general, for each of the component scores, patients with AS scored lower than patients with $\mathrm{AS}+\mathrm{FM}$, with statistically significantly less severe sleep problems on all domains except for use of sleep medication.

Patients with AS and concomitant FM showed poorer quality of life according to ASQoL compared to patients with alone AS $(13.8 \pm 2.35$ vs. 8.6 $\pm 4.01 ; p<0.01)$.

Conclusion: Sleep disturbance is a frequent condition in patients with AS. Our study results demonstrate the significant impact of FM comorbidity on sleep disturbance and quality of life in patients with AS.

\section{REFERENCES}

[1] Bigatti, S. M., Hernandez, A. M., Cronan, T. A., \& Rand, K. L. (2008) Sleep disturbances in fibromyalgia syndrome: relationship to pain and depression. Arthritis Care \& Research: Official Journal of the American College of Rheumatology, 59(7), 961-967.

[2] Leverment, S., Clarke, E., Wadeley, A. et al. (2017) Prevalence and factors associated with disturbed sleep in patients with ankylosing spondylitis and non-radiographic axial spondyloarthritis: a systematic review Rheumatol Int, 37: 257 https://doi.org/10.1007/s00296-016-3589-x

Disclosure of Interests: Iryna Shapoval: None declared, Mykola Stanislavchuk Grant/research support from: AstraZeneca, Celltrion, Galapagos, Genentech, GlaxoSmithKline, Human Genome, Lilly, Medlmmune, Pfizer Roche and UCB, Larysa Perebetiuk: None declared DOI: 10.1136/annrheumdis-2019-eular.1761

\section{SAT0351 IBIS-Q (IBD IDENTIFICATION OF SPONDYLOARTHRYTIS QUESTIONNAIRE): A NEW TOOL TO DETECT SPONDYLOARTHRITIS IN INFLAMMATORY BOWEL DISEASE PATIENTS}

Ilaria Tinazzi ${ }^{1}$, Angela Variol ${ }^{2}$, Antonio Marchetta ${ }^{1}$, Andrea Geccherle ${ }^{2}$ Pierluigi Macchioni ${ }^{3}$, Dennis Mcgonagle ${ }^{4}{ }^{1}$ Sacro Cuore Hospital, Negar-Verona, Italy; ${ }^{2}$ Sacro Cuore Hospital, IBD Unit, Negrar Verona, Italy, ${ }^{3}$ Unit Of Rheumatology, Reggio Emilia, Italy; ${ }^{4}$ NIHR Leeds Musculoskeletal Biomedical Research Unit, Leeds Teaching Hospitals Trust, Leeds, United Kingdom

Background: Extra-intestinal manifestations (EIM) are frequent in IBD with peripheral and axial spondyloarthritis $(\mathrm{SpA})$ being the commonest EIM, being reported in up to $23 \%$ of subjects.. Early detection of $\mathrm{SpA}$ is clinically relevant to drive the therapeutic management including the right treatment at the right time to prevent disability and improve the quality of life. In the literature there are few validated Rheumatology referral models for SpA for gastroenterological use

Objectives: The aim of this study was to develop a questionnaire to identify peripheral and axial SpA in a cohort of IBD patients (setting: IBD Unit of Sacro Cuore-Negrar Hospital Verona in a rheumatological-gastroenterology clinic).

Methods: During a preliminary meeting a group of experts in SpA-IBD (6 rheumatologists and 4 gastroenterologists) generated a list of 42 items thought to cover all possible SpA manifestations including spinal, articular and entheseal involvement. Consecutive patients referred to the IBD Unit were then enrolled from January to May 2018 without excluding patients affected by EIM. Rheumatologic assessment was performed in the same day by a Rheumatologist blinded to the medical story and to the questionnaire results in order to collect data about the 66 swollen joint count (SJC) and 68 TJC, MASEI, LEI, presence of ASAS criteria for axial and peripheral SpA, presence of diagnostic criteria for fibromyalgia (FM) and non-specific low back pain (NSLB) pain mainly due to OA). If the patient presented a tender/swollen entheses, a US exam completed the clinical examination. The patient completed BASDAI and BASFI questionnaires in the same day. Factorial analysis to identify the main factors; ROC curves for sensibility/specificity; Youden index for cut-off were performed.

\section{Table 1}

1. Have you had pain in your heels?

2. Have you ever had back pain lasting at least 3 months that was not injury related?

3. Have you ever had a swollen wrist without having any trauma?

4. Have you ever had a swollen knee without having any trauma?

5. Do you wake up at night and walk because of low back pain?

6. In the morning is your back stiff for more than 30 minutes?

7. Have you ever had a stiff neck for some weeks or months?

8. Have you ever had a pain in your thigh which goes down to your knee and not beyond?

9. Is it difficult to pick things up from the floor without flexing your knees?

10. Have you ever had a swollen finger like a "saugage" for some days?

11. Do you find it difficult to walk because of foot pain?

12. Do you feel pain when people shake your hand?

13. Have you ever had swollen and painful hands?

14. Have you ever had swollen and painful feet?

Results: A final 38-items questionnaire was tested in 210 patients (excluding 17 patients for presence of other rheumatic diseases and 12 for incomplete evaluation). The psychometric analysis of the questionnaire was done on data of 181 patients. 58 patients of the enrolled patients met the ASAS criteria for SpA (13 axial, 5 both axial and peripheral 40 peripheral). The SpA prevalence in our cohort was $32 \%$ with 10 new cases detected by the questionnaire (5.5\%: 7 peripheral and 3 axial). Through the psychometric and factorial analysis, we selected 14 -items to 